\title{
Generalized Fokker-Planck equation for the distribution function of liquidity accumulation
}

\author{
Hnativ B. ${ }^{1}$, Didyk A. ${ }^{2}$, Tokarchuk M. ${ }^{1,3}$ \\ ${ }^{1}$ Lviv Polytechnic National University, \\ 12 S. Bandera Str., 79013, Lviv, Ukraine \\ ${ }^{2}$ Lviv University of Business and Law, \\ 99 Kulparkivska Str., 79021, Lviv, Ukraine \\ ${ }^{3}$ Institute for Condensed Matter Physics of the National Academy of Sciences of Ukraine, \\ 1 Svientsitskii Str., 79011, Lviv, Ukraine
}

(Received 3 March 2019; Revised 23 April 2019; Accepted 30 April 2019)

\begin{abstract}
By means of the method of Zubarev's nonequilibrium statistical operator, the generalized Fokker-Planck equation for the distribution function of liquidity accumulations has been obtained. The generalized velocity and transport kernels describing dynamic correlations between liquidity accumulations of different categories of families have been determined. The system of non-Markov transport equations for non-equilibrium average values of liquidity accumulations for different categories of families has been obtained. Memory effects have been analyzed using the fractional calculus, which has led to a system of transport equations for non-equilibrium average values of liquidity accumulations for different categories of families in fractional derivatives.
\end{abstract}

Keywords: transport equation, memory effects, liquidity accumulations, fractional derivative.

2000 MSC: $35 \mathrm{Q} 80$

UDC: 517.958

DOI: $10.23939 / \mathrm{mmc} 2019.01 .037$

\section{Introduction}

In the field of modern theoretical economics, significant successes are associated with an intensively developing direction which is called "physical economy" [1], which is based on nature laws (laws of physics and basic equations of physical processes transfer). It is natural that modern methods of statistical physics that describe the states of interacting open systems (equilibrium and non-equilibrium, stationary and non-stationary) are used now to describe the evolution of economic systems, in particular the financial markets [2-4]. This direction was formed in the process of developing evolutionary economy [5,6] and synergetic economy [7-10]. The importance and role of the use of modern methods of non-equilibrium statistical physics for the description of economic processes have been substantiated by the authors of the work [11], which presents the dynamic models of micro- and macroeconomics in Russia. Problems of describing economic processes and their prediction, in particular in Ukraine, using statistical methods of mechanics and thermodynamics, are given in [12-16].

In recent years, the economic processes with memory have been actively studied [17-29]. Fractional calculus and fractional differential equations [30-33], which use derivatives and integrals of non-integer orders, are convenient means for description of memory processes in both physical sciences and socioeconomic sciences. A detailed, modern review of the problem of description of economic processes with memory is given in the Tarasovs' work [29].

In this paper, using the Zubarev's non-equilibrium statistical operator [34-36], we have obtained a generalized (non-Markov) Fokker-Planck equation for the function of distribution of liquid accumulation with the definition of generalized velocity and transport kernels describing the dynamic correlations between liquidity accumulations $U_{f}$ and $U_{f^{\prime}}$ of different $f, f^{\prime}$ categories of families. These functions 
are determined in terms of the weight function $W(U)$, which can be calculated by means of methods of functional integration. The non-Markov transfer equations are obtained for non-equilibrium average values of liquidity accumulation in different categories of families. Memory effects in transfer equations have been analyzed using fractional calculus $[30-33,37]$. As a result, we have obtained the transport equation for non-equilibrium average values of liquidity accumulation in different categories of Langevin families in fractional derivatives.

\section{Non-equilibrium function of distribution of liquidity accumulation}

In any modern state, the economic structure is determined by the distribution of elements of this state (families) in terms of liquidity accumulation, which are described by the distribution function $\rho(U ; t)$, where $U$ are accumulations, which include monetary units and securities, which can be quickly and easily converted into money. Property, i.e., a car, an apartment, a house, etc., is not included in liquidity accumulation.

According to the liquidity accumulation, the families can be divided into:

1) rich (high-paid members of the family);

2) wealthy (average paid members of the family);

3) poor (low paid members of the family).

As an indicator of the economic stability of modern, highly developed, successful countries is the relatively high percentage of wealthy families. To describe the economic structure in highly developed countries, the function $\rho(y ; t)$ of families distribution in terms of income is used, where $y$ is the income of the family per unit of time. In this case, the distribution with respect of income is directly determined according to the tax declarations. The distributions $\rho(U)$ and $\rho(y)$ are different though they are interconnected. The functions $\rho(U)$ and $\rho(y)$ can be found using different methods (surveys, data analysis, and expert evaluations). In the developed countries, where the tax system is well organized, the distribution according to the income is directly determined by tax declarations. The distribution according to accumulation can be obtained from the analysis of deposits. In Ukraine, methods give inaccurate results and the method of reconstruction of the economic structure of society (ESS) based on indirect data and expert assessments is more effective.

Since the functions of the distribution $\rho(\hat{U} ; t)$ and $\rho(y ; t)$ are related, then in order to describe the economic structure of society we use the distribution functions $\rho(\hat{U} ; t)$. Obviously, different categories of families in the economic processes of the state will take different average accumulation values over a certain observed time $t$ :

$$
\left\langle\hat{U}_{m}\right\rangle^{t}, \quad\left\langle\hat{U}_{s}\right\rangle^{t}, \quad\left\langle\hat{U}_{n}\right\rangle^{t},
$$

where $\hat{U}_{m}, \hat{U}_{s}, \hat{U}_{n}$ are random functions of accumulation of high paid, middle and low payed families, respectively. The average values in (1) are calculated using the distribution function $\rho(\hat{U} ; t)=\rho\left(\hat{U}=\left\{\hat{U}_{f}\right\} ; t\right)$ :

$$
\langle\ldots\rangle^{t}=\int \ldots \rho(\hat{U} ; t) d \hat{U}
$$

The functions $\hat{U}_{m}, \hat{U}_{s}, \hat{U}_{n}$ in the economic processes undergo nonlinear fluctuations and are related to the purchasing capacity $r_{f}=\frac{U_{f}}{p}$, where $p$ is the price of the product, $f=\{m, s, n\}$. In order to take them into account when calculating the average (1), the averaging operation we present in functional form:

$$
\begin{gathered}
\langle\ldots\rangle^{t}=\int \ldots \nu(U) \rho(U ; t) d U, \\
\nu(U)=\prod_{f} \delta\left(\hat{U}_{f}-U_{f}\right), \\
d U=\left\{d U_{m} d U_{s} d U_{n}\right\},
\end{gathered}
$$


where the functional $\rho(U ; t)$ in the method of a nonequilibrium statistical operator [34] satisfies the generalized non-Markov equation of Fokker-Planck

$$
\begin{aligned}
\frac{\partial}{\partial t} \rho(U ; t)+\sum_{f} \frac{\partial}{\partial U_{f}} & V_{f}(U) \rho(U ; t) \\
& =\sum_{f, f^{\prime}} \frac{\partial}{\partial U_{f}} \frac{1}{W(U)} \int d U^{\prime} \int_{-\infty}^{t} e^{\varepsilon\left(t^{\prime}-t\right)} L_{f, f^{\prime}}\left(U, U^{\prime} ; t, t^{\prime}\right) \frac{\partial}{\partial U_{f^{\prime}}}\left\{\frac{\rho\left(U ; t^{\prime}\right)}{W(U)}\right\} d t^{\prime} .
\end{aligned}
$$

Here $V_{f}(U=\hat{U})$ is the velocity of liquidity accumulation changes by $f=\{m, s, n\}$ th family category:

$$
V_{f}(U)=\frac{\left\langle\nu(U) \dot{\hat{U}}_{f}\right\rangle}{W(U)}
$$

where

$$
\dot{\hat{U}}_{f}=P_{f}(\hat{U})-Q_{f}(\hat{U}),
$$

$P_{f}(\hat{U})$ is the income of $f$-th family, $Q_{f}(\hat{U})$ is the function of demand for the $f$-th family, $\langle\ldots\rangle=$ $\int \ldots \delta(\hat{U}-U) d \hat{U}$.

$$
W(U)=\int \delta(\hat{U}-U) d \hat{U}
$$

is the weight function. $L_{f, f^{\prime}}\left(U, U^{\prime} ; t, t^{\prime}\right)$ are the generalized transport kernels describing dynamic correlations between liquidity accumulations $U_{f}$ and $U_{f^{\prime}}$ of different $f, f^{\prime}$ categories of families:

$$
L_{f, f^{\prime}}\left(U, U^{\prime} ; t, t^{\prime}\right)=\left\langle x_{f}(U) T\left(t, t^{\prime}\right) x_{f^{\prime}}\left(U^{\prime}\right)\right\rangle,
$$

where

$$
\begin{gathered}
x_{f}(U)=(1-\Pi) \nu(U) \dot{\hat{U}}_{f}, \\
\Pi A=\int d U \frac{1}{W(U)}\langle A \nu(U)\rangle \nu(U) .
\end{gathered}
$$

Here $\Pi$ is the projectional operator. $T\left(t, t^{\prime}\right)=e^{-(1-\Pi) i L\left(t-t^{\prime}\right)}$ is the operator of evolution in time, $i L$ is the Liouville operator, which corresponds to model Hamiltonian of the problem:

$$
\begin{gathered}
H=\frac{1}{2} \sum_{f} \hat{V}_{f}^{2}+\sum_{f, f^{\prime}} \Phi\left(f, f^{\prime}\right) \hat{U}_{f} \hat{U}_{f^{\prime}}+\sum_{f, f^{\prime} f^{\prime \prime}} \Phi\left(f, f^{\prime}, f^{\prime \prime}\right) \hat{U}_{f} \hat{U}_{f^{\prime}} \hat{U}_{f^{\prime \prime}}+\ldots \\
\hat{V}_{f}=\frac{d}{d t} \hat{U}_{f}
\end{gathered}
$$

is the velocity of liquidity accumulation of the $f$-th family. $\Phi\left(f, f^{\prime}\right), \Phi\left(f, f^{\prime}, f^{\prime \prime}\right)$ are "potentials" of liquidity accumulation interaction for different categories of families. With this, the condition if satisfied $\langle H\rangle=E=$ const, $E$ is total "energy" of liquidity accumulation. The equation of Fokker-Planck (5) describes the memory effects in the dynamics of correlations between the liquidity accumulations of different categories of families. In the Markov approximation, when the effects of the memory are not taken into account, the equation (5) is of the form:

$$
\frac{\partial}{\partial t} \rho(U ; t)+\sum_{f} \frac{\partial}{\partial U_{f}} V_{f}(U) \rho(U ; t)=\sum_{f, f^{\prime}} \frac{\partial}{\partial U_{f}} L_{f, f^{\prime}}(U) \frac{\partial}{\partial U_{f^{\prime}}}\left\{\frac{\rho(U ; t)}{W(U)}\right\}
$$

where

$$
L_{f, f^{\prime}}(U)=\frac{1}{W(U)} \int d U^{\prime} \int_{-\infty}^{t} e^{\varepsilon\left(t^{\prime}-t\right)}\left\langle x_{f}(U) T\left(t, t^{\prime}\right) x_{f^{\prime}}\left(U^{\prime}\right)\right\rangle
$$

are the coefficients of transfer of liquidity accumulations. 


\section{Generalized transfer equations}

For a more detailed study of the structure of the functions of liquidity accumulations, we assume that the total amount of money in the state is $M(t)$, and it is distributed among all the categories of families according to the rule:

$$
\begin{aligned}
M(t) & =m\left\langle\hat{U}_{m}\right\rangle^{t}+s\left\langle\hat{U}_{s}\right\rangle^{t}+n\left\langle\hat{U}_{n}\right\rangle^{t}, \\
\frac{d}{d t} M(t) & =m \frac{d}{d t}\left\langle\hat{U}_{m}\right\rangle^{t}+s \frac{d}{d t}\left\langle\hat{U}_{s}\right\rangle^{t}+n \frac{d}{d t}\left\langle\hat{U}_{n}\right\rangle^{t} \\
& =J_{M}(t)-J_{M}^{>}(t)+J_{M}^{<}(t),
\end{aligned}
$$

where $J_{M}(t)$ is total flow of money within the state, $J_{M}^{>}(t)$ is the total flow of money out of the state and $J_{M}^{<}(t)$ is the total inflow of money to the state. $N=m+s+n$ is the total number of families in the state. By analyzing (7), we can see that the income and demand of each family, according to the equation of non-equilibrium economic processes (13) is the basis of liquidity savings, a significant proportion of which in highly developed countries enters into money circulation through production, new scientific technologies, and securities. And this, in turn, affects the total flow of money $J_{M}(t)$, $J_{M}^{>}(t), J_{M}^{<}(t)$, balance of which determines the stability of the state. $P_{f}(\hat{U})$ and $Q_{f}(\hat{U})$ are interrelated that can be explored on a simple physical model of market economy of the closed society. The structure of the Fokker-Planck equation greatly depends on the calculations of the structural function $W(U)[36]$. The Gaussian approximation for $W(U)$ can be obtained by the method of collective variables in the form [36]:

$$
W^{G}(U)=Z^{-1} \exp \left\{-\frac{1}{2} \sum_{f, f^{\prime}}\left[\tilde{M}_{2}\right]_{f f^{\prime}}^{-1} U_{f} U_{f^{\prime}}-\frac{1}{2} \ln \pi \operatorname{det} \tilde{M}_{2}\right\},
$$

$\left[\tilde{M}_{2}\right]_{f f^{\prime}}^{-1}$ are the elements of matrix inverse to the matrix $\tilde{M}_{2}$, the elements of which are paired correlation functions $M_{2}^{f f^{\prime}}=\left\langle\hat{U}_{f} \hat{U}_{f^{\prime}}\right\rangle_{0},\langle\ldots\rangle_{0}=\int \ldots \rho_{0}(\hat{U}) d \hat{U}, \rho_{0}(\hat{U})$ is equilibrium distribution of accumulation for all categories of families, $Z$ is its statistical sum. Having calculated in Gaussian approximation all the characteristics in the Fokker-Planck equation (5), for the average values $\left\langle\hat{U}_{m}\right\rangle^{t},\left\langle\hat{U}_{s}\right\rangle^{t},\left\langle\hat{U}_{n}\right\rangle^{t}$ we obtain a system of non-Markov transport equations for the average values of liquidity accumulations of different categories of families:

$$
\frac{\partial}{\partial t}\left\langle\hat{U}_{f}\right\rangle^{t}+\sum_{f^{\prime}} i \Omega_{f f^{\prime}}\left\langle\hat{U}_{f^{\prime}}\right\rangle^{t}-\sum_{f^{\prime}} \int_{-\infty}^{t} e^{\varepsilon\left(t^{\prime}-t\right)} \Xi_{f f^{\prime}}\left(t, t^{\prime}\right)\left\langle\hat{U}_{f^{\prime}}\right\rangle^{t^{\prime}} d t^{\prime}=0
$$

where

$$
i \Omega_{f f^{\prime}}=\sum_{f^{\prime \prime}}\left\langle\dot{\hat{U}}_{f} \hat{U}_{f^{\prime \prime}}\right\rangle_{0}\left[\tilde{M}_{2}\right]_{f^{\prime \prime} f^{\prime}}^{-1}
$$

is the frequency matrix,

$$
\Xi_{f f^{\prime}}\left(t, t^{\prime}\right)=\sum_{f^{\prime \prime}}\left\langle I_{f}(\hat{U}) T_{0}\left(t, t^{\prime}\right) I_{f^{\prime \prime}}(\hat{U})\right\rangle_{0}\left[\tilde{M}_{2}\right]_{f^{\prime \prime} f^{\prime}}^{-1}
$$

are memory functions that describe dissipative processes when changing savings between different categories of families in the society.

$$
I_{f}(\hat{U})=(1-P) \dot{\hat{U}}_{f}
$$

are the generalized flows, $P$ are projection operator Mori $[35,36]$, which has the following structure:

$$
P \hat{A}=\sum_{f^{\prime \prime} f^{\prime}}\left\langle\hat{A} \hat{U}_{f^{\prime \prime}}\right\rangle_{0}\left[\tilde{M}_{2}\right]_{f^{\prime \prime} f^{\prime}}^{-1} \hat{U}_{f^{\prime}}
$$

and has the following properties $P(1-P)=0, P \hat{U}_{f}=\hat{U}_{f}$.

The obtained system of equations (18) for the average values of accumulations is closed and takes into account collective dissipative processes of changes in accumulations among different categories of families. It contains memory and can be applied to the description of the processes of sharing the 
accumulation between different categories of families in the society for the given rules (11), guaranteed by the state. Calculation of memory functions (20) is complex, therefore, for the analysis of memory effects in the process of changing the accumulation between different categories of families, we take certain approximations for functions (20). To do this, using the Fourier transform with respect to time to the equation (18), we obtain:

$$
i \omega\left\langle\hat{U}_{f}\right\rangle_{\omega}+\sum_{f^{\prime}} i \Omega_{f f^{\prime}}\left\langle\hat{U}_{f^{\prime}}\right\rangle_{\omega}-\sum_{f^{\prime}} \Xi_{f f^{\prime}}(\omega)\left\langle\hat{U}_{f^{\prime}}\right\rangle_{\omega}=0
$$

Note that in Gaussian approximation, the functions $i \Omega_{f f^{\prime}}=0$. Further, for them $\Xi_{f f^{\prime}}(\omega)$ we take:

$$
\Xi_{f f^{\prime}}(\omega)=W_{f f^{\prime}}(\omega) \bar{\Xi}_{f f^{\prime}}
$$

where $\bar{\Xi}_{f f^{\prime}}=\Xi_{f f^{\prime}}(\omega=0)$. Having modeled $W_{f f^{\prime}}(\omega)$ in the form:

$$
W_{f f^{\prime}}(\omega)=\frac{\left(i \omega \tau_{f^{\prime}}\right)^{\gamma-1}}{i \omega\left(1+\left(i \omega \tau_{f}\right)^{\xi-2}\right)}, \quad 0<\gamma<1, \quad 0<\xi<1,
$$

the equation (21), we rewrite as follows:

$$
(i \omega)^{2}\left(1+\left(i \omega \tau_{f}\right)^{\xi-2}\right)\left\langle\hat{U}_{f}\right\rangle_{\omega}=\sum_{f^{\prime}} \tau_{f^{\prime}}^{\gamma-1}(i \omega)^{\gamma-1} \bar{\Xi}_{f f^{\prime}}\left\langle\hat{U}_{f^{\prime}}\right\rangle_{\omega}
$$

Here $\tau_{f}$ characteristic relaxation times of changes in liquidity savings, and $\left\langle\hat{U}_{f}\right\rangle_{\omega}$ is Fourier mapping for non-equilibrium average values of liquidity accumulations of the family from the category $f$. Then we use the Fourier transform to fractional derivatives of functions:

$$
L\left({ }_{0} \mathrm{D}_{t}^{\xi-1} f(t) ; i \omega\right)=(i \omega)^{\xi-1} L(f(t) ; i \omega),
$$

where $\omega$ is the frequency and ${ }_{0} \mathrm{D}_{t}^{\xi-1} f(t)=\frac{1}{\Gamma(\xi)} \frac{d}{d t} \int_{0}^{t} \frac{f(\tau)}{(t-\tau)^{1-\xi}} d \tau$ is the Riemann-Liouville fractional derivative.

Using it, the inverse transform in the equation (24) to time dependencies gives the transport equation in fractional derivatives:

$$
\frac{\partial^{2}}{\partial t^{2}}\left\langle\hat{U}_{f}\right\rangle^{t}+\tau_{f}^{\xi-2}{ }_{0} \mathrm{D}_{t}^{\xi}\left\langle\hat{U}_{f}\right\rangle^{t}=\sum_{f^{\prime}} \tau_{f^{\prime}}^{\gamma-1}{ }_{0} \mathrm{D}_{t}^{\gamma-1} \bar{\Xi}_{f f^{\prime}}\left\langle\hat{U}_{f^{\prime}}\right\rangle^{t},
$$

The system of transport equations (26) for non-equilibrium average values of liquidity savings of different categories of families is closed. The key issue for further research is the calculation of the transport kernels $\bar{\Xi}_{f f^{\prime}}$, which describe the correlations between the velocities of liquidity accumulation of different categories of families at zero frequency.

\section{Conclusion}

Using the method of Zubarev's non-equilibrium statistical operator, we have obtained a generalized (non-Markov) Fokker-Planck's equation for the nonequilibrium distribution function of liquidity accumulations in different categories of families. The definition of generalized velocity and transport kernels are given, which describe the dynamic correlations between liquidity accumulation $\hat{U}_{f}$ and $\hat{U}_{f^{\prime}}$ of different $f$ and $f^{\prime}$ categories of families. These functions are determined in terms of weight function $W(U)$, which can be calculated by functional integration methods. In Gaussian approximation for $W(U)$ using the Fokker-Planck equation, the system of non-Markov transport equations for non-equilibrium average values of liquidity accumulations for different categories of families has been obtained. Memory effects have been analyzed using the fractional calculus, which has led to a system of transport equations for non-equilibrium average values of liquidity accumulations for different categories of families in fractional derivatives. 
[1] LaRouche L. The Science of Physical Economy as the Platonic Epistemological Basis for All Branches of Human Knowledge. Executive Intelligence Review. 21 (9-11), (1994).

[2] Mantegna R. N., Stanley H.E. An introduction to econophysics. Correlations and complexity in finance. Cambridge, Cambridge University Press (1999).

[3] Bouchaud J.-P., Potters M. Theory of financial risks. Cambridge, Cambridge University Press (2000).

[4] Voit J. The statistical mechanics of financial markets. Berlin-Heidelberg, Springer-Verlag (2001).

[5] Mayevsky V. I. Introduction to evolutionary economics. Moscow, Japan today (2000), (in Russian).

[6] Nelson R. R., Winter S. J. Evolutionary theory of economic change. Moscow, Delo (2000), (in Russian).

[7] Pu T. Nonlinear economic dynamic. Izhevsk, Udmurt. university (2000), (in Russian).

[8] Zhang V.-B. Synergetic economics: Time and changes in non-linear economic theory. Berlin-Heidelberg, Springer (1991).

[9] Lebedev V. V. Mathematical modeling of socio-economic processes. Moscow, Isograph (1997), (in Russian).

[10] Olemskoi A. I., Yushchenko O. V. The synergetic picture of the financial market, evolving in accordance with the incoming information. Economic regulation mechanism. 1, 112-117 (2003), (in Russian).

[11] Chernavskii D. S., Starkov N. I., Shcherbakov A.V. On some problems of physical economics. PhysicsUspekhi. 45 (9), 977-997 (2002).

[12] Yukhnovsky I. R. The program of the future. Selected Works. Economics. Lviv Polytechnic National University, pp. 3-18 (2005), (in Ukrainian).

[13] Hnativ B. V., Tokarchuk R. M., Kostrobij P.P., Tokarchuk M. V. Mathematical modeling of economic processes by method of nonequilibrium statistical mechanics. J. Lviv Polytechnic National University, Physical mathematical sciences. 696, 93-100 (2011), (in Ukrainian).

[14] Dmytryshyn L.I. Ecophysical aspects of the formation of the function of distribution of wealth and income in socio-economic systems. Modeling of Regional Economics: Proceedings. 1, 96--102 (2012), (in Ukrainian).

[15] Dmytryshyn L. I. Kinetic models of distribution of money income of the population. Modeling of Regional Economics: Proceedings. 2, 50-62 (2012), (in Ukrainian).

[16] Moroz K. V. Income distribution of the population of Ukraine: Empirical analysis using lognormal function. Visnik Harkivs'kogo nacional'nogo universitetu imeni V. N. Karazina. Serija "Ekonomichna". 91, 110-117 (2016), (in Ukrainian).

[17] Baillie R. T. Long memory processes and fractional integration in econometrics. J. Econometrics. 73, 5-59 (1996).

[18] Scalas E., Gorenflo R., Mainardi F. Fractional calculus and continuous-time finance. Physica A. 284, 378$384(2000)$.

[19] Mainardi F., Raberto M., Gorenflo R., Scalas E. Fractional calculus and continuous-time finance II: The waiting-time distribution. Physica A. 287, 468-481 (2000).

[20] Laskin N. Fractional market dynamics. Physica A. 287, 482-492 (2000).

[21] Gorenflo R., Mainardi F., Scalas E., Raberto M. Fractional calculus and continuous-time finance III: the diffusion limit. Mathematical Finance. 171-180 (2001).

[22] Raberto M., Scalas E., Mainardi F. Waiting-times and returns in high-frequency financial data: an empirical study. Physica A. 314, 749-755 (2002).

[23] Teyssiere G., Kirman A. P. Long Memory in Economics. Berlin-Heidelberg, Springer-Verlag (2007).

[24] Škovránek T., Podlubny I., Petráš I. Modeling of the national economies in state-space: A fractional calculus approach. Economic Modelling. 29 (4), 1322-1327 (2012).

[25] Tarasova V. V., Tarasov V. E. Elasticity for economic processes with memory: fractional differential calculus approach. Fractional Differential Calculus. 6 (2), 219-232 (2016).

[26] Tarasov V.E., Tarasova V. V. Time-dependent fractional dynamics with memory in quantum and economic physics. Ann. Phys. 383, 579-599 (2017).

[27] Tarasova V.V., Tarasov V.E. Economic interpretation of fractional derivatives. Prog. Fractional Diff. Appl. 3 (1), 1-7 (2017). 
[28] Tarasov V.E., Tarasova V.V. Macroeconomic models with long dynamic memory: Fractional calculus approach. Appl. Math. Comp. 338, 466-486 (2018).

[29] Tarasova V.V., Tarasov V.E. Concept of dynamics memory in economics. Comm. Nonlin. Sci. Numer. Simul. 55, 127-145 (2018).

[30] Samko S. G., Kilbas A. A., Marichev O. I. Fractional Integrals and Derivatives: Theory and Applications. New York, Gordon and Breach (1993).

[31] Podlubny I. Fractional Differential Equations. San Diego, Academic Press (1998).

[32] Kilbas A. A., Srivastava H. M., Trujillo J. J. Theory and Applications of Fractional Differential Equations. Amsterdam, Elsevier (2006).

[33] Diethelm K. The Analysis of Fractional Differential Equations: An Application-Oriented Exposition Using Differential Operators of Caputo Type. Berlin, Springer-Verlag (2010).

[34] Zubarev D. N., Khazanov A. M. Generalized Fokker-Planck equation and construction of projection operators for different methods of reduced description of nonequilibrium states. Theor. Math. Phys. 34 (1), 43-50 (1978).

[35] Zubarev D. N., Morozov V. G., Röpke G. Statistical mechanics of nonequilibrium processes, vol. 2. Moscow, Fizmatlit (2002), (in Russian).

[36] Hlushak P. A., Tokarchuk M. V. Chain of kinetic equations for the distribution functions of particles in simple liquid taking into account nonlinear hydrodynamic fluctuations. Physica A. 443, 231-245 (2016).

[37] Kostrobij P. P., Markovych B. M., Viznovych O. V., Tokarchuk M. V. Generalized transport equation with nonlocality of space-time. Zubarev's NSO method. Physica A. 514, 63-70 (2019).

\title{
Узагальнене рівняння Фоккера-Планка для функції розподілу ліквідних накопичень
}

\author{
Гнатів Б. ${ }^{1}$, Дідик А. ${ }^{2}$, Токарчук M. ${ }^{1,3}$ \\ ${ }^{1}$ Національний університет "Лъвівсъка політехніка", \\ вул. С. Бандери, 12, Лъвів, 79013, Україна \\ 2 Львівський університет бізнесу та права, \\ вул. Кульпарківсъка, 99, Львів, 79021, Украӥна \\ ${ }^{3}$ Інститут фізики конденсованих систем НАН Украӥни, \\ вул. Свенціиъкого, 1, Лъвів, 79011, Україна
}

\begin{abstract}
За допомогою методу нерівноважного статистичного оператора Зубарева отримано узагальнене рівняння Фоккера-Планка для функції розподілу ліквідних накопичень. Визначено узагальнену швидкість та ядра переносу, що описують динамічні кореляції між ліквідними накопиченнями різних категорій сімей. Отримано систему немарковських рівнянь переносу для нерівноважних середніх значень ліквідних накопичень для різних категорій сімей. Ефекти пам'яті проаналізовано із застосуванням апарату дробового числення, що привело до системи рівнянь переносу для нерівноважних середніх значень ліквідних накопичень для різних категорій сімей у дробових похідних.

Ключові слова: рівняння переносу, ефекти пам'яті, ліквідні накопичення, дробові похідні.
\end{abstract}

2000 MSC: $35 \mathrm{Q} 80$

УдК: 517.958

Mathematical Modeling and Computing, Vol. 6, No. 1, pp.37-43 (2019) 